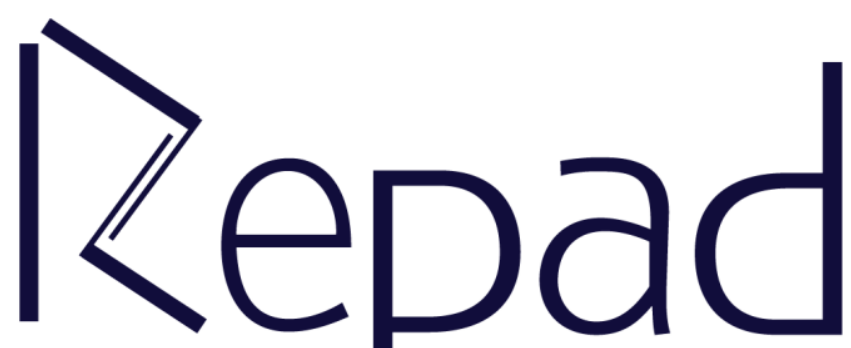

vol. 3, n. 3, Setembro-Dezembro/2019

Revista Estudos e

Pesquisas em Administração

(C) (i) This work is licensed under a Creative Commons Attribution 4.0 International License 


\title{
CONCESSÕES AEROPORTUÁRIAS BRASILEIRAS, SAÚDE FINANCEIRA E PRÁTICA REGULATÓRIA: Uma aplicação do modelo Fleuriet
}

\author{
Eduardo Da Silva Pereira \\ Universidade de Brasília, Brasília, Distrito Federal, Brasil \\ edufeliz.ep@gmail.com \\ https://orcid.org/0000-0002-0872-3903 \\ Carlos Henrique Rocha \\ Universidade de Brasília, Brasília, Distrito Federal, Brasil \\ https://orcid.org/0000-0002-1143-2058
}

\section{Resumo}

Este artigo análisa a saúde financeira dos aeroportos brasileiros da $2^{\mathrm{a}}$ rodada de concessão com o modelo Fleuriet. Nessa rodada foram concedidos os aeroportos de Guarulhos, Viracopos e Brasília. O modelo Fleuriet seccionou as contas do ativo e passivo circulantes e do balanço patrimonial tradicional em ativo errático, ativo cíclico, passivo errático e passivo cíclico. Os seus principais indicadores foram capital de giro, necessidade de capital de giro e saldo de tesouraria. Infere-se que os três aeroportos gozaram de precária saúde financeira entre 2013 e 2017. A taxa de concessão apresentou peso expressivo no passivo cíclico dos aeroportos, impactando o saldo de tesouraria. Os resultados aqui apresentados podem servir para aperfeiçoar a prática regulatória.

Palavras-chave: concessões aeroportuárias, modelo Fleuriet, saúde financeira.

\section{BRAZILIAN AIRPORT GRANTS, FINANCIAL HEALTH AND REGULATORY PRACTICE: An application of the Fleuriet model}

\begin{abstract}
This article analyzes the financial health of Brazilian airports of the 2nd round of concession with the Fleuriet model. In this round were granted the airports of Guarulhos, Viracopos and Brasilia. The Fleuriet model has sectioned the current assets and liabilities accounts of the traditional balance sheet into erratic assets, cyclical assets, erratic liabilities and cyclical liabilities. Its main indicators were working capital, working capital requirements and cash balance. It is inferred that the three airports had poor financial health between 2013 and 2017. The concession rate had a significant weight in the cyclical liabilities of the airports, impacting the treasury balance. The results presented here may serve to improve regulatory practice.
\end{abstract}

Keywords: airport concessions, Fleuriet model, financial health

Submetido: 02/09/2019

Aceito: 20/12/2019

INTRODUÇÃO

Publicado: 31/12/2019

No mundo contemporâneo tem sido comum o governo conceder as empresas públicas para a iniciativa privada. Essa passagem pode ser feita por duas formas principais: privatização e concessão. A privatização ocorre quando o governo vende em definitivo empresas estatais para a iniciativa privada. A concessão é uma privatização temporária e regulada (MEGGINSON; NETTER, 2001). 
Em 2010, o Brasil lançou o programa de concessões aeroportuárias. O objetivo do programa é usar o capital privado para melhorar e desenvolver os aeroportos nacionais, além de reduzir a demanda por recursos do governo.

O primeiro aeroporto concedido foi o de São Gonçalo do Amarante no Rio Grande do Norte, em 2011. No ano seguinte, foram os aeroportos de Guarulhos e Viracopos em São Paulo e de Brasília no Distrito Federal. Os aeroportos do Galeão no Rio de Janeiro e Confins em Minas Gerais foram concedidos aos privados em 2013. A quarta rodada, em 2017, envolveu a concessão de quatro aeroportos. Após a quinta rodada de concessão em março de 2019 são vinte e dois aeroportos concedidos.

Compreender a performance financeira da atividade concedida é de importância para a afinação da prática regulatória. Um dos principais objetivos da prática regulatória é monitorar e encorajar a eficiência das operações, com repercussão nas finanças das empresas concedidas. Registre-se que uma concessão em dificuldades financeiras decerto não será operacionalmente eficiente (DECKER, 2014).

O objetivo deste artigo é analisar a saúde financeira dos aeroportos de Guarulhos, Viracopos e Brasília; ou na linguagem IATA (International Air Transport Association), GRU, VCP e BSB, nesta ordem. Os três aeroportos são da $2^{\mathrm{a}}$ rodada de concessão. Os aeroportos de Guarulhos, Viracopos e Brasília respondem por $30 \%$ do total do tráfego de passageiros no Brasil (BRASIL, 2018). O período amostral compreende os anos de 20132017. Esses aeroportos foram escolhidos em função da disponibilidade das demonstrações financeiras de cinco anos. Os dados da pesquisa foram obtidos do site da Agência Nacional de Aviação Civil (ANAC).

A análise emprega o modelo dinâmico de Fleuriet, Kehdy e Blanc (1980). O modelo representa uma inovação em relação a análise estática por índices financeiros tradicionais, observam Braga (1991), Marques e Braga (1995), Melo e Coutinho (2007) e Souza e Bruni (2008).

O modelo Fleuriet tem sido aplicado as mais variadas atividades econômicas como empresas financeiras e não-financeiras listadas na bolsa de valores (AMBROZINI et al., 2014); (FRANCISCO et al., 2012); (MELO; COUTINHO, 2007); (PRADO et al., 2018), fábricas da indústria de transformação (ROCHA; KLANN; HEIN, 2010); (SOUZA; BRUNI, 2008), companhias aéreas (BARBOSA; SANTOS; BARBOSA, 2016), cooperativas agropecuárias (GIMENES; GIMENES, 2006), empresas do agronegócio (JONES; JACINTO, 2013), hospital (CORRÊA; RITTA, 2017) e empresas brasileiras de seguro (FONSECA et al., 2001).

Depois de feita busca nas principais bases de publicação do Brasil e do mundo, constatou-se que não existe trabalho relacionando concessões dos transportes com o modelo Fleuriet, oferecendo uma motivação para este artigo, que pode ser classificado como descritivo, quantitativo e explicativo (MARTINS; THEÓPHILO, 2007).

A questão de pesquisa que orienta este artigo é: o modelo Fleuriet é capaz de explicar a performance financeira dos aeroportos brasileiros concedidos?

\section{CONCESSÕES AEROPORTUÁRIAS}

\section{Breve histórico das concessões no mundo e Brasil}

As concessões aeroportuárias no mundo iniciaram em 1987 no Reino Unido. Depois, outros países seguiram a iniciativa britânica como Austrália, Canadá, Nova Zelândia, estados-membros da União Européia, México, Chile e Índia (GILLEN, 2011). 
Baird (2000) apresenta um arcabouço de gradação de privatização, segundo funções essenciais, mostrando de maneira útil o leque de opções de privatização disponível para as autoridades públicas (Quadro 1). Neste Quadro o regulador é o agente regulador, o dono do terreno é o proprietário da infraestrutura de transporte e o provedor da função é o agente que presta os serviços.

Quadro 1. Modelo de governança de infraestruturas de transporte, segundo funções essenciais

\begin{tabular}{|lccc|}
\hline & \multicolumn{3}{c|}{ Funções essenciais } \\
\cline { 2 - 4 } Modelo de governança & Regulador & Dono do terreno & Provedor da função \\
\hline I. Público & Público & Público & Público \\
II.Público/privado & Público & Público & Privado \\
III.Privado/público & Público & Privado & Privado \\
IV.Privado & Privado & Privado & Privado \\
\hline
\end{tabular}

Fonte: Adaptado de Baird (2000)

O Reino Unido adotou o modelo III de governança de Baird (2000) enquanto boa parte dos países optou pelo modelo II (AUGUSTYNIAK, 2009), inclusive o Brasil.

Os Estados Unidos tentaram aderir as concessões aeroportuárias no final de 2007 com o aeroporto de Chicago Midway. A transação não foi adiante por causa da crise financeira mundial de 2008 e, posteriormente, a ideia foi abandonada. Em 2013, o aeroporto Luis Munoz Marin em San Juan, do estado americano de Porto Rico, foi privatizado (POOLE; EDWARDS, 2016).

Alguns dos benefícios da privatização aeroportuária incluem maior eficiência operacional, melhores serviços e aumento do investimento de capital (POOLE; EDWARDS, 2016; PRATT, 2015). Mas, as formas de concessão de aeroportos entre países diferem desde a regulação de tarifas, propriedade do aeroporto (participações societárias nacionais e estrangeiras) e forma de operação (GILLEN, 2011).

Para Silveira e Quintilhano (2019), os resultados das concessões aeroportuárias brasileiras são preocupantes e comprometem o futuro da aviação brasileira, pois não contribuem para o desenvolvimento da aviação nacional.

No Brasil, as concessões aeroportuárias começaram em 2011 com o aeroporto de São Gonçalo do Amarante (RN). Esta concessão foi a única até o momento do tipo greenfield; inexistia qualquer infraestrutura pronta no local. No presente, são vinte e dois aeroportos concedidos e já foram realizadas cinco rodadas de concessão (Quadro 2).

Ao contrário do exposto por Silveira e Quintilhano (2019), as concessões aeroportuárias alavancaram investimentos e melhoram o nível de serviço dos aeroportos conforme salienta o Relatório de Desempenho Operacional dos Aeroportos do primeiro trimestre de 2018, elaborado pelo, então, Ministério dos Transportes, Portos e Aviação Civil, em obediência ao Decreto $n^{\circ} 6.780$, de 18 de fevereiro de 2009. 
Quadro 2. Aeroportos brasileiros concedidos entre 2011 e 2019

\begin{tabular}{|c|c|c|c|c|c|}
\hline Aeroporto & Estado & Ano/Fase & Aeroporto & Estado & Ano/Fase \\
\hline São Gonçalo do Amarante & $\mathrm{RN}$ & $2011 / 1^{a}$ & Maceió & $\mathrm{AL}$ & $2019 / 5^{a}$ \\
\hline Guarulhos & SP & $2012 / 2^{\mathrm{a}}$ & João Pessoa & PB & $2019 / 5^{\mathrm{a}}$ \\
\hline Viracopos & SP & $2012 / 2^{\mathrm{a}}$ & Aracaju & SE & $2019 / 5^{\mathrm{a}}$ \\
\hline Brasilia & $\mathrm{DF}$ & $2012 / 2^{\mathrm{a}}$ & Juazeiro do Norte & $\mathrm{CE}$ & $2019 / 5^{\mathrm{a}}$ \\
\hline Galeão & RJ & $2013 / 3^{\mathrm{a}}$ & Campina Grande & PB & $2019 / 5^{\mathrm{a}}$ \\
\hline Confins & MG & $2013 / 3^{\mathrm{a}}$ & Cuiabá & MT & $2019 / 5^{\mathrm{a}}$ \\
\hline Pinto Martins & $\mathrm{CE}$ & $2017 / 4^{\mathrm{a}}$ & Sinop & MT & $2019 / 5^{\mathrm{a}}$ \\
\hline Luiz Eduardo Magalhães & BA & $2017 / 4^{\mathrm{a}}$ & Rondonópolis & MT & $2019 / 5^{\mathrm{a}}$ \\
\hline Hercílio Luz & $\mathrm{SC}$ & $2017 / 4^{\mathrm{a}}$ & Alta Floresta & MT & $2019 / 5^{\mathrm{a}}$ \\
\hline Salgado Filho & RS & $2017 / 4^{\mathrm{a}}$ & Vitória & ES & $2019 / 5^{\mathrm{a}}$ \\
\hline Recife & $\mathrm{PE}$ & $2019 / 5^{a}$ & Macaé & RJ & $2019 / 5^{\mathrm{a}}$ \\
\hline
\end{tabular}

Fonte. Brasil (2018)

\section{Aspectos regulatórios dos aeroportos brasileiros concedidos}

O dinamismo do marco regulatório dos aeroportos é perceptível, segundo Pereira (2019). As primeiras medidas regulatórias das concessões aeroportuárias emergiram no leilão do aeroporto São Gonçalo do Amarante quando a agência reguladora e representante do poder concedente, a ANAC, estipulou como regime regulatório as seguintes condições: os proponentes deveriam ser pessoas jurídicas brasileiras ou estrangeiras, podendo concorrer isoladamente ou em consórcio, ficando limitada à participação de pessoas jurídicas declaradas inidôneas, impedidas de licitar e contratar com a administração pública, condenada por crimes ambientais, dirigentes ou responsáveis técnicos que tenham trabalhado na ANAC e Ministério da Defesa nos últimos 180 dias, anteriores ao lançamento do edital. Foi também vedada à participação de empresas aéreas, suas controladoras, controladas e coligadas, isoladamente ou em consórcio com participação igual ou superior a 10\%. A autoridade reguladora exigiu a criação de uma Sociedade de Propósito Específico (SPE) para a gestão do aeroporto.

Já na segunda rodada ficou estabelecido como temas regulatórios adicionais: (a) a participação de entidades de previdência complementar e fundo de investimento, (b) a participação da estatal Infraero (Empresa Brasileira de Infraestrutura Aeroportuária) com 49\% da SPE, (c) o estabelecimento de um acordo de acionistas para disciplinar a sociedade entre o ente privado e a estatal (Infraero) e (d) o estabelecimento de obrigações de investimento em infraestrutura aeroportuária iniciais e faseados.

A Infraero não participou da $4^{\mathrm{a}} \mathrm{em}$ diante. Portanto, a totalidade da operação aeroportuária e governança da concessão foram para mãos da iniciativa privada. As autoridades incentivaram a participação de investidores internacionais nos leilões. Por exemplo, a operadora aeroportuária singapurana Changi Airports International atualmente opera o Galeão, a francesa Vinci Airports opera o aeroporto de Salvador e a Suíça Zurich International Airport AG opera o aeroporto de Florianópolis e permitiu ainda a participação de um mesmo operador em mais de um aeroporto a exemplo da alemã Fraport AG Frankfurt Airport Services que opera os aeroportos de Fortaleza e Porto Alegre, ambos da $4^{a}$ rodada. Já na $5^{a}$ rodada a operadora espanhola AENA Desarrollo Internacional SME S/A arrematou os aeroportos do Bloco Nordeste e a suíça ZURICH Airport Latin America LTDA os do Bloco Sudeste. 
Os aeroportos são leiloados na Bolsa de Valores, Mercadorias e Futuros de São Paulo atual Brasil Bolsa Balcão (B3). O governo estabelece por meio de estudo de viabilidade econômica o valor mínimo do certame. Na ocasião do leilão, os interessados apresentam propostas em envelopes fechados. As três maiores propostas disputam um leilão do tipo inglês. No início, o valor ofertado pelo vencedor do leilão era pago e diluído durante o prazo da concessão. Desde a $4^{\mathrm{a}}$ rodada, uma parcela $(25 \%)$ do valor de aquisição do aeroporto é do tipo downpayment. O objetivo desta medida foi o de tornar os valores dos lances do leilão inglês mais realistas.

O valor pago anualmente pelos aerooportos para o governo é chamado de outorga, taxa de concessão ou contraprestação, figurando no passivo circulante do balanço patrimonial do aeroporto concedido. O montante de recurso arrecadado pelo governo com a taxa de concessão abastece o Fundo Nacional de Aviação Civil (FNAC). O FNAC é um fundo criado em 2011 com o propósito de fomentar o desenvolvimento da infraestrutura de aviação civil nacional. Registra-se um crescimento de mais de $800 \%$ nos aportes ao FNAC no período de 2012 (R $\$ 1,2$ bilhão) a 2017 (R \$9,7 bilhões), resultado dos leilões aeroportuários. As ações prioritárias para aplicação dos recursos incluem manutenção e aprimoramento da infraestrutura aeronáutica e aeroportuária públicas (TEIXEIRA, 2018).

Como mudança regulatória na $5^{\mathrm{a}}$ rodada de concessões, o aporte inicial para o FNAC no ato da assinatura do contrato de concessão, passou a incluir o equivalente à metade do valor mínimo de leilão fixado pelo governo mais a metade do ágio (diferença entre o valor de oferta e o valor mínimo) eventualmente decorrente da disputa entre os proponentes.

Isto, acrescentado da obrigação de pagamento da outorga ou taxa de concessão variável sobre a receita bruta da concessão, estabelecida em percentuais crescentes do $6^{\circ}$ ao $10^{\circ}$ ano, tornando-se constante a partir daí até o final da concessão (BRASIL, 2019).

A principal inovação da $5^{\text {a }}$ rodada foi a substituição da outorga fixa pela contribuição variável, buscando adequar os contratos às oscilações de demanda e, consequentemente, de receita na vigência da concessão (BRASIL, 2019).

Os contratos de concessão preveem medidas regulatórias para o caso de descontinuidade ou precarização do serviço prestado pelas concessionárias, se resguardando de eventos dentre eles a caducidade, encampação, recisão, anulação e falência. Um importante ponto regulatório é que a norma brasileira vigente de concessão de aeroportos permite que se avance nos direitos creditícios e no capital social dos patrocinadores dos aeroportos nessas situações.

Outra característica regulatória importante é a exigência por parte do poder concedente de garantia contratual, visando assegurar o fiel cumprimento de todas as obrigações contraídas pela concessionária perante o governo, nos termos do contrato firmado. Dentre estas, destaca-se a obrigatoriedade de contratação de apólice de segurogarantia, em que o segurado é a ANAC e o contratante do seguro é a concessionária, para fins de cobertura de inadimplência quanto ao pagamento de taxas de concessão, caducidade contratual e disputas judiciais.

\section{AEROPORTO E AMBIENTE DE NEGÓCIO}

Um aeroporto é uma firma multiprodutos e, na sua forma mais simples, possui dois tipos de negócio. Um associado ao mercado do lado do ar como companhias aéreas de passageiros e de cargas, operadores aeroportuários e passageiros. Outro dissociado do mercado do ar como locatários comerciais e empresas de planejamento de embarque e 
desembarque de passageiros (GILLEN, 2011; JONES; DUNSE, 2015). As concessões aeroportuárias brasileiras funcionam exatamente desta forma.

As concessionárias brasileiras são remuneradas por meio das receitas tarifárias e não tarifárias, as primeiras são compostas pela tarifa de embarque, tarifa de conexão, tarifa de pouso, tarifa de permanência, tarifa de armazenagem e tarifa de capatazia. As receitas coletadas com as referidas tarifas dependem do número de passageiros, do número de aeronaves em trânsito, do tempo de permanência em solo e do volume de carga processada nos aeroportos (BRASIL, 2019).

As receitas não tarifárias são auferidas por meio do arrendamento de áreas comercias, que possibilitam a exploração do sítio aeroportuário com a venda de bens e serviços, com a instalação de shoppings, hotéis e parques de estacionamentos. Este tipo de receita fornece um razoável grau de atratividade para o empreendimento aeroporto, representando em média 35\% das receitas totais da concessão (BATTAL; BAKIR, 2017). Nos aeroportos da Europa, as receitas dos negócios não relacionados à aviação representam em média 44\% do total das receitas, diz Jones e Dunse (2015)

Para Vojvodić (2008), as receitas aeroportuárias permitem ainda ao concessionário custear a manutenção do aeroporto e realizar investimentos na infraestrutura. Isto justifica as estratégias implantadas para tal tal fim como: aumento do espaço comercial nos terminais, políticas de marketing e preços adotadas a partir do perfil dos passageiros, monitoramento do comportamento de compras dos usuários e incentivos e facilidades para a realização de conexões de voos. As privatizações e concessões de aeroportos os convertem em corporações privadas pagadoras de impostos (VOJVODIĆ, 2008).

No caso do Brasil, as receitas não tarifárias dão origem a outorga variável, percentual das receitas anuais brutas que é recolhido ao FNAC, como forma de remunerar o poder concedente.

\section{MODELO FLEURIET: TEORIA}

\section{Introdução ao Modelo}

O balanço patrimonial de uma empresa apresenta dois grandes grupos de contas: ativo e passivo. O passivo é dividido em passivo circulante, passivo não circulante e patrimônio líquido; essas contas descrevem a configuração do capital emprestado a empresa. $\mathrm{O}$ ativo é dividido em ativo circulante e ativo não circulante, pormenorizando como o capital emprestado é usado pela empresa.

O modelo Fleuriet dividiu as contas do ativo circulante e do passivo circulante do balanço patrimonial em ativo errático, ativo cíclico, passivo errático e passivo cíclico. $\mathrm{O}$ Quadro 3 apresenta a estrutura do balanço patrimonial do modelo Fleuriet. A redefinição das contas baseou-se no conceito de atividades operacionais e alheias a essas atividades, notam Fleuriet e Zeidan (2015).

Quadro 3. Balanço Patrimonial do modelo Fleuriet

\begin{tabular}{|l|l|}
\hline Ativo errático & Passivo errático \\
\hline Ativo cíclico & Passivo cíclico \\
\hline Ativo não circulante & Passivo não circulante \\
\hline & Patrimônio líquido \\
\hline Ativo Total & Passivo Total \\
\hline
\end{tabular}

Fonte. Adaptado de Fleuriet e Zeidan (2015) 
O ativo errático representa os disponíveis para uso imediato, como também aqueles que são esperados serem convertidos em dinheiro proximamente. $\mathrm{O}$ ativo cíclico refere-se as aplicações operacionais como estoques, despesas antecipadas, créditos fiscais e adiantamentos a fornecedores. O passivo errático representa as fontes de recursos financeiros de curto prazo como empréstimos, pagamentos de cupons e dividendos. $\mathrm{O}$ passivo cíclico descreve as obrigações de ordem operacional tais como salários de funcionários, impostos e fornecedores (FLEURIET; ZEIDAN, 2015).

O modelo Fleuriet tem três variáveis principais: (a) capital de giro $(C D G)$, (b) necessidade de capital de giro (NCG) e (c) saldo de tesouraria (T). Barbosa, Santos e Barbosa (2016) e Fleuriet e Zeidan (2015) assinalam que essas variáveis são úteis para monitorar a liquidez e a saúde da empresa, além de suportar decisões estratégicas quanto a sua estrutura de capital.

Do desmembramento das contas do ativo circulante e do passivo circulante podese calcular os indicadores $C D G, N C G$ e $T$, assim:

$$
\begin{aligned}
& C D G=P N C+P L-A N C \\
& N C G=A C I-P C I \\
& T=A E-P E
\end{aligned}
$$

Em que CDG é o capital de giro, PNC é o passivo não circulante, PL é o patrimônio líquido, $A N C$ é o ativo não circulante, $N C G$ é a necessidade de capital de giro, $A C I$ é o ativo cíclico, $P C I$ é o passivo cíclico, $T$ é o saldo de tesouraria, $A E$ é o ativo errático e PE é o passivo errático.

Sabe-se da identidade do balanço patrimonial do modelo Fleuriet que:

$A E-P E=P C I+P N C+P L-A C I-A N C$

A partir da organização dos termos da equação (4), é possível obter a equação (5):

$$
A E-P E=(P N C+P L-A N C)-(A C I-P C I)
$$

Usando as definições das equações (1) e (2) e substituindo (4) em (3) para obter:

$T=C D G-N C G$

A equação (1) representa as fontes de recursos disponíveis de longo prazo e a equação (2) as aplicações que precisam ser financiadas. Se $N C G$ for positivo e crescentemente maior do que $C D G(C D G>0)$, o saldo de tesouraria, equação (3a), se aprofunda negativamente, surgindo o chamado efeito tesoura. Isto porque o gap entre $N C G$ e $C D G$ se assemelha a abertura das lâminas de uma tesoura (FLEURIET; ZEIDAN, 2015). 


\section{Tipos de balanço patrimonial e regras de decisão do modelo Fleuriet}

Originalmente, o modelo Fleuriet possuía quatro tipos de balanço patrimonial (BP) e regras de decisão. Braga (1991) adicionou outros dois tipos de BP e regras (Quadro 4).

Quadro 4. Tipo de balanço patrimonial e regra de decisão do modelo Fleuriet

\begin{tabular}{|l|c|c|c|c|}
\hline Regra & Tipo de BP & CDG & NCG & T \\
\hline Excelente & 1 & + & - & + \\
\hline Sólida & 2 & + & + & + \\
\hline Insatisfatória & 3 & + & + & - \\
\hline Alto risco & 4 & - & - & + \\
\hline Muito ruim & 5 & - & - & - \\
\hline Péssima & 6 & - & + & - \\
\hline
\end{tabular}

Fonte. Adaptado de Marques e Braga (1995). Nota. $\mathrm{BP}=$ balanço patrimonial, $\mathrm{CDG}=$ capital de giro, $\mathrm{NCG}=$ necessidade de capital de giro $(\mathrm{NCG})$ e $\mathrm{T}=$ saldo de tesouraria.

Uma empresa do tipo 1 apresenta saldo de tesouraria positivo e recebe pagamentos adiantados por bens e serviços em produção. Uma empresa do tipo 2 é considerada sólida financeiramente. Uma empresa do tipo 3 apresenta necessidade de capital de giro maior do que o montante de capital de giro, impactando negativamente o saldo de tesouraria. Uma empresa do tipo 4 exibe saldo de tesouraria positivo porque a necessidade de capital de giro é negativa e maior do que o capital de giro, em termos absolutos. Uma empresa do tipo 5 exibe situação financeira ruim. Uma empresa do tipo 6 com capital de giro negativo reforça o saldo negativo de tesouraria, dado que a necessidade de capital de giro é positiva. Uma empresa do tipo 3, 5 e 6 opera com saldo de tesouraria negativo, revelando uma dependência exagerada de financiamentos a curto prazo, podendo levá-las a um estado falimentar. Uma empresa do tipo 4 e 5 não possui fundos para servir suas atividades operacionais (FLEURIET; ZEIDAN, 2015; VIEIRA, 2008).

\section{PROCEDIMENTOS METODOLÓGICOS}

Para se alcançar o objetivo proposto neste artigo lançou-se mão do seguinte esquema metodológico:

a) uso da técnica de revisão sistemática de literatura onde, pode-se verificar as produções existentes sobre o tema estudado nas bases científicas da Web of Science, Scopus e Science Direct, com o uso dos constructos airport and model Fleuriet" e "airport and model Fleuriet and concession", tal pesquisa embasa o ineditismo da aplicação do modelo Fleuriet no estudo de concessões aeroportuárias;

b) realização do panorama sobre as concessões aeroportuárias brasileiras e o modelo de negócio adotado;

c) investigação e coleta de dados no banco eletrônico da ANAC, onde obteve-se informações acerca dos leilões e as demonstrações financeiras no período de 2013 a 2017 dos aeroportos brasileiros concedidos da $2^{\mathrm{a}}$ rodada de leilões;

d) tratamento dos dados coletados subdividido nas seguintes atividades: realização de auditoria dos dados, estudo das notas explicativas dos balanços patrimoniais dos exercícios fiscais e adequação dos dados coletados ao formato do modelo Fleuriet; 
e) segue-se com a aplicação do modelo Fleuriet onde, reclassificou-se as contas dos balanços patrimoniais e endereçou-se a situação de cada concessão de acordo com os parâmetros de Fleuriet;

f) em consonância, se faz a análise dos resultados obtidos com a aplicação do modelo Fleuriet, a fim de se aferir a saúde financeira das concessões aeroportuárias;

g) e por fim faz -se as considerações finais, conclusões e recomendações para trabalhos futuros.

\section{DISCUSSÃO E RESULTADOS}

Antes de avaliar a saúde financeira dos aeroportos de GRU, VCP e BSB foi preciso converter os seus balanços patrimoniais convencionais de 2013-2017 em balanços patrimoniais no formato do modelo Fleuriet. Lembrando que as contas: ativo não circulante, passivo não circulante e patrimônio líquido não se alteram.

O Quadro 5 sintetiza o conjunto de componentes do ativo errático, passivo errático, ativo cíclico e passivo cíclico do modelo Fleuriet.

Quadro 5. Contas e subcontas do modelo Fleuriet

\begin{tabular}{ll}
\hline Ativo errático & Passivo errático \\
\hline Disponibilidades & Duplicatas descontadas \\
Aplicações financeiras & Adiantamento de câmbio \\
Títulos e valores mobiliários & Empréstimos e Financiamentos Bancários \\
Créditos contra empresas coligadas & Dívidas com empresas coligadas \\
Outras & Outras
\end{tabular}

\begin{tabular}{ll}
\hline Ativo cíclico & Passivo cíclico \\
\hline Duplicatas a receber & Duplicatas a pagar \\
Adiantamento a fornecedores & Salários, encargos e impostos produtivos \\
Impostos produtivos a recuperar & Adiantamento de clientes \\
Estoques & Participações de empregados a pagar \\
Outras contas operacionais & Outras contas operacionais \\
\hline
\end{tabular}

Fonte. Fleuriet e Zeidan (2015) e Pereira Filho (1998)

Depois, foram calculados para cada um dos três aeroportos e para os anos da amostra (2013-2017) os indicadores de capital de giro $(C D G)$, necessidade de capital de giro $(N C G)$ e saldo de tesouraria $(T)$, apresentados na Tabela 1. Diga-se que de acordo com a definição de contas cíclicas do passivo do modelo Fleuriet a taxa de concessão é um de seus componentes.

\section{Análise dos resultados}

Para os três aeroportos no decorrer desses cinco anos os ativos permanentes foram maiores do que os passivos permanentes $(\mathrm{CDG}<0)$. Isto representa que os fundos de longo prazo não foram suficientes para financiar a totalidade dos ativos permanentes nesses anos. 
Tabela 1. Indicadores do modelo Fleuriet para Guarulhos, Viracopos e Brasília (20132017) em milhões de R\$

\begin{tabular}{|c|c|c|c|c|c|c|c|c|c|}
\hline \multirow{2}{*}{ Ano } & \multicolumn{3}{|c|}{ Guarulhos (GRU) } & \multicolumn{3}{|c|}{ Brasilia (BSB) } & \multicolumn{3}{|c|}{ Viracopos (VCP) } \\
\hline & $\mathrm{CDG}$ & NCG & $\mathrm{T}$ & $\mathrm{CDG}$ & NCG & $\mathrm{T}$ & $\mathrm{CDG}$ & NCG & $\mathrm{T}$ \\
\hline 2013 & $-625,27$ & $-1.246,56$ & 621,29 & $-745,1$ & $-260,6$ & $-484,6$ & $-184,6$ & $-205,9$ & 21,31 \\
\hline 2014 & $-938,45$ & $-1.118,56$ & 180,11 & $-239,3$ & $-282,4$ & 43,07 & $-444,1$ & $-373,7$ & $-70,4$ \\
\hline 2015 & $-1.165,42$ & $-1.185,76$ & 20,34 & $-158,9$ & $-244,9$ & 85,98 & $-234,1$ & $-266,7$ & 32,55 \\
\hline 2016 & $-1.516,19$ & $-1.430,26$ & $-85,93$ & $-277,9$ & $-285,2$ & 7,33 & $-477,5$ & $-487,7$ & 10,27 \\
\hline 2017 & $-750,75$ & $-2.214,88$ & $1.464,13$ & -627 & $-70,63$ & $-556,4$ & $-631,7$ & $-680,3$ & 48,57 \\
\hline Média * & $-1084,8$ & $-1552,36$ & 467,56 & $-448,8$ & $-253,7$ & $-195,2$ & $-422,4$ & $-430,3$ & 7,95 \\
\hline
\end{tabular}

Fonte: Elaborado a partir de Brasil (2018). Nota. * Média a preços de 2017.

Os primeiros anos de existência da concessão aeroportuária costumam exigir maiores investimentos para adequar a infraestrutura aeroportuária ao nível exigido. A Tabela 2 exibe os investimentos dos três aeroportos no período 2013-2016. Como pode ser visto, os investimentos exigidos têm caído com o tempo.

Tabela 2. Investimentos realizados nos aeroportos de GRU, VCP e BSB (R \$ milhões)

\begin{tabular}{ccccc}
\hline \multirow{2}{*}{ Aeroporto } & \multicolumn{4}{c}{ Ano } \\
\cline { 3 - 6 } & 2013 & 2014 & 2015 & 2016 \\
GRU & $3.290,00$ & $1.483,30$ & 298 & 134,8 \\
VCP & $1.693,50$ & $1.439,00$ & 422,5 & 271,8 \\
BSB & $1.160,70$ & 938,3 & 96,3 & 53,9 \\
\hline
\end{tabular}

Fonte: Elaborado a partir de Brasil (2018)

Os passivos cíclicos dos três aeroportos foram maiores do que os ativos cíclicos. Como pode ser visto no item 5.2.1, a taxa de concessão respondeu por grande parte desse resultado. $\mathrm{O}$ saldo de tesouraria dos aeroportos foi predominantemente positivo porque $N C G>C D G$, em termos absolutos. Em média, e de acordo com os dados da Tabela 2, pode-se dizer que os aeroportos de Guarulhos e Viracopos apresentaram balanço patrimonial de alto risco e o de Brasília muito ruim no período analisado.

\section{Taxa de concessão}

A participação média da taxa de concessão no passivo cíclico total dos três aeroportos foi expressiva, como mostrado na Tabela 3.

Tabela 3. Participação média da taxa de concessão/passivo cíclico (2013-2017)

\begin{tabular}{cccc}
\hline Período & Guarulhos & Viracopos & Brasilia \\
\hline $2013-2016$ & $77 \%$ & $43 \%$ & $55 \%$ \\
2017 & $40 \%$ & $38 \%$ & $4 \%$ \\
\hline
\end{tabular}

Fonte. Elaborado a partir de Brasil (2018)

Como se depreende da Tabela 3 o pagamento de taxas de concessão (outorgas) teve um impacto expressivo no passivo cíclico no período de 2013-2016 dos três aeroportos. Em 2017, os aeroportos de Guarulhos e Brasília reprogramaram os valores e prazos de liquidação das taxas de concessão, conforme previsto na Lei ${ }^{\circ} 13.499$, de 26 de outubro de 2017, que estabelece critérios para a celebração de aditivos contratuais 
relativos às outorgas nos contratos de parceria no setor aeroportuário. Um dos critérios estabelecidos na referida lei para o reperfilamento de dívidas é a adimplência do interessado com as outorgas vencidas até a data de assinatura do termo aditivo. $\mathrm{O}$ aeroporto de Viracopos não repactuou a sua dívida com o governo porque foi incapaz de quitar as outorgas em atraso.

É importante considerar que a participação média da taxa de concessão de Viracopos (43\%) no seu passivo cíclico seria maior se o aeroporto tivesse pago regularmente a taxa. $\mathrm{O}$ aeroporto amortizou parte da dívida referente as outorgas e lançou o saldo devedor no passivo não circulante. Nota-se que apesar do crescimento do número de passageiros após a concessão em 2012, conforme Figura 1, as receitas geradas não fizeram frente aos compromissos com a taxa de concessão e as dívidas de financiamento para os investimentos iniciais na infraestrutura aeroportuária.

Figura 1. Evolução do número de passageiros por ano em milhões.

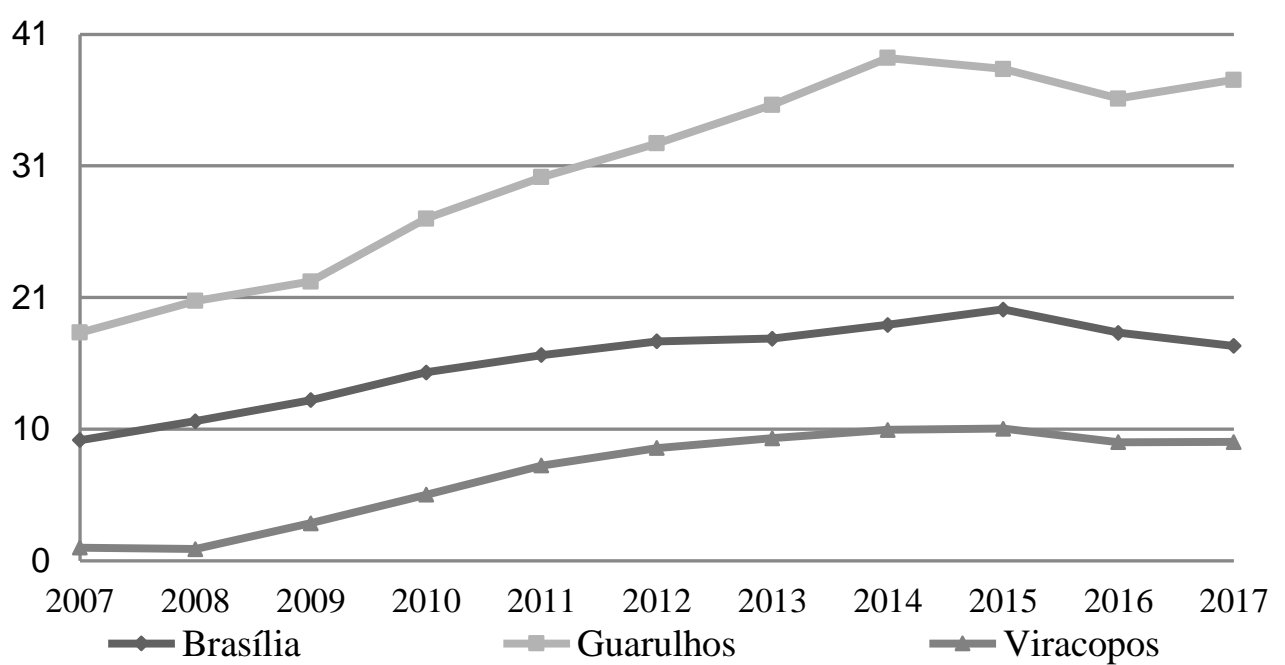

Fonte: Adaptado de BRASIL(2018)

Entre 2012 e 2017, o número de passageiros no aeroporto de Viracopos cresceu modestamente em 1,04\% ao ano. Em Brasília, o número de passageiros caiu nesse período. Essa constatação reforça a situação financeira ruim dos aeroportos de Viracopos e Brasília comparada a de Guarulhos.

\section{CONSIDERAÇÕES FINAIS}

Este artigo avaliou a saúde financeira dos aeroportos de Guarulhos, Viracopos e Brasília mediante o emprego do modelo Fleuriet. O período analisado compreendeu os anos de 2013 a 2017. Os balanços patrimoniais tradicionais desses aeeroportos foram obtidos do site da ANAC. Registre-se que não há trabalho relacionando concessões dos transportes com o modelo Fleuriet. Esta lacuna forneceu a justificativa para este artigo.

Da avaliação, infere-se que os três aeroportos nos cinco anos estudados gozaram de precária saúde financeira. Isto foi devido, particularmente, a dois fatores: (a) investimentos requeridos nos primeiros anos das concessões e (b) taxa de concessão. Os investimentos caíram com o tempo, aliviando o capital de giro, ao passo que a outorga permanece até o vencimento da concessão, pressionando a necessidade de capital de giro via passivo cíclico. 
Como trabalho futuro, pode-se testar estatisticamente se a afinação regulatória, ocorrida entre 2017 e 2018, repercutiu favoravelmente nas finanças dos aeroportos da quarta rodada relativamente aos aeroportos das rodadas anteriores. A afinação regulatória diz respeito à ausência da Infraero no consórcio vencedor do leilão e ao pagamento à vista de parcela da outorga.

Enfim, o artigo limitou-se a avaliar a saúde financeira dos aeroportos brasileiros concedidos na $2^{\text {a }}$ rodada e não apurou a necessidade anual de caixa desses aeroportos de 2018 para frente e até o final da concessão para manter as suas contas em equilíbrio.

\section{REFERÊNCIAS}

AMBROZINI, M. A.; MATIAS, A. B.; PIMENTA JÚNIOR, T. Análise dinâmica de capital de giro segundo o modelo Fleuriet: uma classificação das empresas brasileiras de capital aberto no período de 1996 a 2013 . Revista Contabilidade Vista \& Revista, v. 25 , n. 2, p. 15-37. 2014.

AUGUSTYNIAK, W. Impact of privatization on airport performance: analysis of Polish and British airports. Journal of International Studies, v. 2, n. 1, p. 59-65. 2009.

BAIRD, A. J. Port privatisation: objectives, extent, process and the U.K. experience. International Journal of Maritime Economics, 2(3): 177-194. 2000.

BARBOSA, S. C.; SANTOS, F. J.; BARBOSA, A. G. Modelo Fleuriet: aplicação de um estudo de caso no setor de transporte aéreo. 2016. Disponível em <http://www.crc.org.br/Arquivos/Publicacoes/2018/livro_felurietpdf.pdf >. Acesso em: 04 de março de 2019.

BATTAL, U.; BAKIR, M. The current situation and change in airport revenues: research on the Europe's five busiest airports. International. Journal of Academic Research in Business and Social Sciences, v. 7, n. 7, p. 287-303. 2017.

BRAGA, R. Análise avançada do capital de giro. Cadernos de Estudos, São Paulo, n. 3, p. 1-20. 1991. Disponível em: <http://www.anac.gov.br>. Acesso em: 12 abril de 2018.

BRASIL. Agência Nacional de Aviação Civil . Anuário do transporte aéreo. Disponível em: 〈http://www.anac.gov.br>. Acesso em: 23 maio de 2018.

BRASIL. Agência Nacional de Aviação Civil . Governo obtém R\$ 2,377 bilhões em concessão de aeroportos em blocos. Disponível em: $<$ https://www.anac.gov.br/noticias/2019/governo-obtem-r-2-377-bilhoes-em-concessaode-aeroportos-em-blocos. $>$. Acesso em: 14 abril de 2019.

CORRÊA, R.; RITTA, C. O. Análise da situação financeira de capital de giro de um hospital filantrópico do sul do Brasil. Revista de Administração Hospitalar e Inovação em Saúde, v. 14, n. 4, p. 1-18. 2017.

DECKER, C. Modern economic regulation: an introduction to theory and practice. $1^{\mathrm{o}}$ ed. Cambridge (UK); Cambridge University Press, 2014.

FLEURIET, M.; ZEIDAN, R. O modelo dinâmico de gestão financeira. $1^{\circ}$ ed. Rio de Janeiro; Alta Books, 2015.

FLEURIET, M.; KEHDY, R.; BLANC, G. A dinâmica financeira das empresas brasileiras. Belo Horizonte; Fundação Dom Cabral, 1980. 
FONSECA, F. V. M.; AMARAL, H. F.; PEREIRA FILHO, A. D.; FRANÇA, R. C.; OLIVEIRA, A. F. C. S. Análise das principais empresas seguradoras do brasil segundo o modelo dinâmico de gestão financeira. In: VII CONGRESO INTERNACIONAL DE COSTOS Y II CONGRESO DE LA ASOCIACIÓN ESPAÑOLA DE CONTABILIDAD DIRECTIVA 2001, Léon. Anais. Léon: 2001

FRANCISCO, J. R. S.; AMARAL, H. F.; DUOA, A. F. ; BERTUCCI, L. A. Gestão financeira do segmento bancos como processo de tomada de decisão: aplicação do modelo dinâmico. Pensar Contábil, v. 14, n. 55, p. 41 - 51. 2012.

GILLEN, D. The evolution of airport ownership and governance. Journal of Air Transport Management, v. 17, n. 1, p. 3-13. 2011.

GIMENES, R. M. T.; GIMENE, F. M. P. Cooperativismo agropecuário os desafios do financiamento das necessidades líquidas de capital de giro. Revista de Economia Contemporânea, v. 10, n. 2, p. 389-410. 2006.

JONES, C.; DUNSE, N. The valuation of an airport as a commercial enterprise. Journal of Property Investment and Finance, v. 33, n. 6, p. 574-585. 2015.

JONES, G. D. C.; JACINTO, A. C. O. (2013). Análise da gestão dos investimentos em capital de giro por meio do modelo Fleuriet em uma empresa do agronegócio: um estudo de caso. Revista em Agronegócios e Meio Ambiente, v.6, n.1, p. 9-30, jan./abr. 2013

MARQUES, J. A. V. C.; BRAGA, R. A dinâmica do capital de giro: o modelo Fleuriet. Revista de Administração de Empresas, v. 35, n. 3, p. 49-63. 1995.

MARTINS, G, A.; THEÓPHILO, C. R. Metodologia da investigação científica para ciências sociais aplicadas. São Paulo: Atlas. 2007.

MEGGINSON, W. L.; NETTER, J. M. From state to market: a survey of empirical studies on privatization, Journal of Economic Literature, v. 39, n. 2, p. 321-389. 2001.

MELO, A. C.; COUTINHO, E. S. O modelo fleuriet como indicador conjunto de solvência e rentabilidade. In: XXXI ENCONTRO DA ANPAD, 2007, Rio de Janeiro. Anais. Rio de Janeiro: 2007.

PEREIRA, E. S. Concessões aeroportuárias, finanças e regulação: uma aplicação do modelo Fleuriet. Brasília: Dissertação de Mestrado (PPGT-UnB). 2019.

PEREIRA FILHO, A. D. O modelo dinâmico de gestão financeira de empresas: procedimentos de operacionalização. Revista Contabilidade Vista \& Revista, v. 9, n. 4, p. 12-22. 1998.

POOLE, R.; EDWARDS, C. Privatizing U.S. airports. Tax and Budget Bulletin, n. 76, p. 1-7. 2016. Disponível em: <https://www.cato.org/sites/cato.org/files/pubs/pdf/tbb76_1.pdf>. Acesso em: 14 abril de 2019.

PRADO, J. W.; CARVAlhO, F. M.; BENEDiCTO, G. C.; AlCÂNTARA, V. C.; SANTOS, A. C. Uma abordagem para análise do risco de crédito utilizando o modelo Fleuriet. Revista de Educação e Pesquisa em Contabilidade, v. 12, n. 3, p. 341-363. 2018.

PRATT, M. M. Airport privatization: aspects, issues, and challenges. London: Nova Science Publishers. 2015. 
ROCHA, I.; KLANN, R.C.; HEIN, N. Utilização do modelo Fleuriet na análise da gestão do capital de giro de empresas brasileiras do setor de siderurgia. In: XVII CONGRESSO BRASILEIRO DE CUSTOS. 2010, Belo Horizonte. Anais. Belo Horizonte: 2010.

SILVEIRA, M.; QUINTILHANO D. Os efeitos das concessões aeroportuárias no Brasil entre os anos de 2012 a 2018. Florianópolis: Geosul, v.34, nº 70 p.87-112.jan/abr. 2019.

SOUZA, S. M.; BRUNI, A. L. Risco de crédito, capital de giro e solvência empresarial: um estudo na indústria brasileira de transformação de cobre. Revista Universo Contábil, v. 4 , n. 2, p. 59-74. 2008.

TEIXEIRA, S. H. O. Planejamento corporativo e concessão aeroportuária no Brasil. Mercator, v. 17, n. 2, p. 1-15. 2018.

VIEIRA, M. V. Administração estratégica do capital de giro. São Paulo: Atlas. 2008.

VOJVODIC, K. Airport Concession. Ekon. Misao Praksa Dubrovnik, god XVII, p. 95104. 2008. 